\title{
Soil Fertility Review using Fuzzy Logic
}

\author{
Gunasekaran Prabakaran *, Dhandapani Vaithiyanathan**and Madhavi Ganesan*** \\ *Department of Electronics and Communication Engineering, College of Engineering Guindy, Anna University, Chennai, India . \\ **Department of Electronics and Communication Engineering, National Institute of Technology Delhi, Delhi, India. \\ ***Centre for Water Resources Engineering, College of Engineering Guindy, Anna University, Chennai, India. \\ Corresponding Author: kgp.com@outlook.com
}

\begin{abstract}
The goal of the study is to improve and maintain the soil fertility. Fundamentally the term soil fertility covers larger proposition and often encompass environmental issues. There had been many attempts addressing the hurdles encountered in ensuring soil fertility. Analyzing the data about the fertilizers consumption by the farmers, we demonstrate the effectiveness of fuzzy based system in achieving maximum productivity together with high cognizance to soil fertility. The proposed fuzzy systems address the solution of the soil luxuriance hurdles in terms of pesticides poisoning especially farmland. The usage of pesticides poses a serious threat to the health of the environment affecting adversely the future generations. On the other hand, it is important not only to preserve soil fertility but also to plant the crops as well. The proposed work have been constructed based on the usage of fertilizers with diverse cropping pattern randomly selected during a pair of cropping cycle and found that the repetition of the cycle failing miserably as the soil fertility gravely damaged. The suggested procedure will enhance the environmental ecosystem and improving the socio-economic status of farmers. Moreover, this increase in the farm products has a positive impact to the Gross Domestic Product (GDP) of a country.
\end{abstract}

Keywords: Soil fertility; Fuzzy system; Law of minimum; Sustainable agriculture.

\section{INTRODUCTION}

The idea of preserving soil fertility has been the most prevalent since from the 19th century (Russell, Edward John 1913, Sanchez, P. A. 2002, Krishna KR 2002 \& Banwart, Steve 2011 ). The claim that soil fertility is protected by crop rotation has made mental changes to people, but we have to take into consideration the fact that people believe in such a change in nominal alteration (Benincasa, Paolo, et al.2017). To this end, maintaining soil fertility is one of the most important needs in the world to prevent over-fertilization and adverse environmental hazards (Fu, HaiMei, et al.2020). In such cases, the proper way of fertilization application process plays a very important role (Mazur, Robert, et al.2017). But, moreover, there are some other important constants and parameters that depend on it. Therefore, technical support is needed to correct this, but at the same time, it is important to note that this technically feasible activity for farmers has traditionally been paltry on some times (Pradesh, A. 2011 \& Osbahr, H., \& Allan, C. 2003). Because, agriculture is often like a shield, hence it has to be passed down from one generation to the next generation. Only then do the farmers feel obligated to stick with old-fashioned methods, and only with the support of the land can they maintain everything from working seasons to crop harvesting practices. In such a situation, following the traditional farming practices, soil fertility and sustainable development can be achieved. This is because it is catalyst for global growth, green growth and sustainable growth (Schjoerring, J.K., Cakmak, I. and White, P.J., 2019.). At the same time, there are several problems encountered, and it is very challenging to solve problems from with different constants like this. Except for the fuzzy logic to deal with them, the way in which many of the values that are 
characteristic of their ambiguity. Fuzzy is become the most appropriate concept to handle multiple vagueness values into single unit. Besides, fuzzy logic has already been used in numerous other forms of soil fertility applications (Stahr, K. and Clemens, G, 2017, Ogunleye, G. O et al.2018 \& Mora-Herrera, Denys Yohana, et al. 2020). In order to reflect this confidence, our proposed system is designed to preserve the soil fertility with fuzzy technology and has been prepared without any nutrient damage to the plant. Therefore, It is important to accelerate its work to reduce fertilizer requirements for agriculture, and it is assumed that a variety of factors affect their livelihood. However, the farmers face the hurdles and to sustain their livelihood through the way of various agricultural practices. Meanwhile, adapt the new technological platform related negotiations is not an easy task, it required minimum duration of time. Accordingly, this research was carried out by the geographical structure of the population of two different climates and two scientific knowledge. People from these two different part of agro climate zones made the same mistakes. Geographically, the places of Coimbatore and Kancheepuram have been the different parts of the district in TamilNadu and line on the Indian country. Coimbatore is found one of the most popular agriculture practices in TamilNadu. In other words, Kancheepuram was being on the poorer of agricultural technological impact district of TamilNadu. The objectives of the study are few streams in agricultural practice districts in TamilNadu and affect the soil fertility for cultivating the purpose of crop. Among the stream well-settled agricultural practices districts in TamilNadu was examined to reduce the fertilizer consumptions in their land and to improving the benefit-cost ratio, cost of cultivation and maintain soil fertility. A few factors are inevitable when looking at the angle of protecting soil fertility. It has been given a little more extensively. $\mathrm{pH}$ of the soil represents either the presence of the $\mathrm{H}+$ ion activity in the soil denoting acidic conditions and $\mathrm{OH}$ - showing alkaline conditions in the soil. A slightly acid pH range of 6-7 is most favoured for plant growing conditions. Better plant growth and climate parameters ensure relief from pest attacks. The soil $\mathrm{pH}$ impacts solubility and therefore shows a direct correlation to the nutrient availability in the soil (Alam, S. M. Naqvi, S. S. M \& Ansari, Raaziuddin 1999). A soil pH below 5.5 generally means a low availability of Ca, Mg, P which affect crop yield, and increased solubility of Fe, AI and Boron. A soil pH above 7.8 shows high availability of $\mathrm{Ca}$ and $\mathrm{Mg}$ and even of $\mathrm{P}, \mathrm{B}, \mathrm{Fe}, \mathrm{Zn}$, and $\mathrm{Cu}$. High temperature, humidity, rainfall, evaporation and wind speed all affect crop yield. Climatic parameters go hand in hand with soil parameters to suit certain crops in specific geographies, and when plants are taken out of their locality, care must be taken to mitigate the adverse effects of the new climatic zone. Both these parameters represent a Law of minimum wherein the less favourable of any one of the parameters determine the yield of the crop even if the other parameters are highly favourable. The figure 1 shows a worldwide accepted law of minimum, concerning the parameters in consideration. 


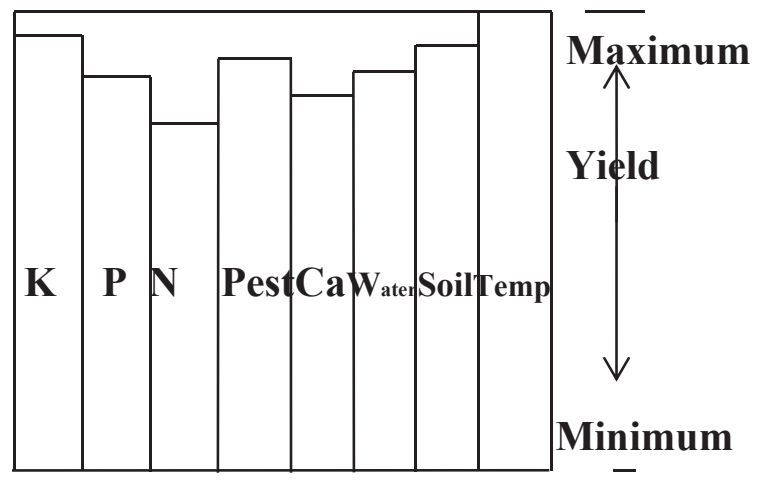

Figure 1. Law of Minimum

In 1905 it was introduced as the linear model and was later broadened by Blackman to be accepted worldwide as concept of Law of Minimum. The Law of Minimum states that a final production of yield is determined by the factor which is the most limiting. Fig. 1 has been provided with the data explaining the Law of Minimum (Chen, Xin-Ping, et al.2011). Soil fertility principles are reported in the soils of Bangladesh and Plant nutrition and soil fertility manual (Sibuga, K. K., and K. P. Sibuga, 1987 \& Huq, SM Imamul, and Jalaluddin Md Shoaib, 2013). The term soil fertility represents the combination of physical structure (texture, profile death, water holding capacity) and some chemical properties such as $\mathrm{pH}$ and levels of essential minerals. Soil fertility determines the crops best suited for the cropping routines in multiple crops systems. Soil Fertility Management is divided into two,

I. Establishing and managing the soil $\mathrm{pH}$

II. Traditional and cultural crop management practices best suited for the Soil $\mathrm{pH}$

\section{SOIL FERTILITY}

The fertility of the soil is the ability of the soil tz least 14 nutrients required for plant growth processes without the concentration of other toxic components. Hence, soil fertility is the huge nutrient status potential of soil to produce healthy crop. The study area consists of six types of soils. Water and salts in the soil are responsible electrical conductivity. A Proper range of electrical conductivity ensures proper transportation of macro and micro nutrients from soil to the various parts of the plants. High electrical conductivity refers to the accumulation of salt in the soil. Generally, the soil electrical conductivity is directly proportional to the temperature if the temperature level is increased the electrical conductivity is also increased. The nominal ranges of soil electrical conductivity lies between from 0.063 to 1.019 and water electrical conductivity lies between 0.24 to 2.36. Pest attacks are one of the major threats to a good crop yield. In order to get the best yield, sufficient preparation for pest incidence needs to be in place. However, the cost of controlling the pest is taken care to lie below the value of the crop destroyed by applying cognizance to Economic Threshold Level (ETL). This is to be calculated by experts and must be kept in mind during system implementation to avoid overspending on pesticides (Jones Jr, J. Benton . 2012, Bueno, A. F., et al.2013, Onstad, David W.1987, Šeremešić, Srđan, et al. 2013 \& Smith, Ray F, 1969 ). India has two crop seasons viz., Rabi and Kharif seasons, apart from that farmers also cultivate during mid-summer period. Not all the crops are equally approachable with a particular fertilizer recommendation; we have to consider various essential factors such as climatic conditions, soil suitability, availability of irrigation facility and various other parameters. During drier seasons, a considerable percentage of cultivable land is left fallow for want of water. If there is a shift in favour of irrigated systems during dry seasons, it means a good market price for the crops are expected. Therefore, other nodal codes have been utilized to exceed the nitrogen, total phosphorus, total potassium, available phosphorus, available potassium and $\mathrm{pH}$ value, including soil organic matter, to increase soil fertility based on the above ground. 


\section{STUDY SITE DESCRIPTION}

The study's North Eastern Zone of TamilNadu lies between $11^{\circ} 00^{\prime}$ to $12^{\circ} 00^{\prime}$ latitudes and zEconomics and Statistics, Government of TamilNadu report mentions that the North Eastern Zone $\mathrm{h}$ as a total geographical area of $4,432 \mathrm{~km} 2$ and coastline of $57 \mathrm{~km} 2$. The study's Western Zone is located at $11.0161^{\circ} \mathrm{N} 76.971^{\circ} \mathrm{E}$ and the total geographical area covered is $7469 \mathrm{~km} 2$. The experimental setup was made of 80 fields located in the above mentioned two agro-climatic zones of Tamil Nadu. In addition, the major soil textures of both the agro-climatic zones were generally clay, loam, sand, clay loam, clay loam sand, and clay-sand (Government of TamilNadu Department of Economics and Statistics, 2015).

\section{SYSTEM DESIGN}

The system is based on fuzzy logic decision making (Ross, Timothy J.2004 \&, Lee, Kwang Hyung, 2004). The system design process is based on crop nutrition-based cultivation practices and minimal use of high-productivity fertilizers and fertilization schedules. The parameters to be taken into consideration are so abundant that it cannot be analyzed using traditional methods, thus requiring a fuzzy logic system. The design nominal parameters of this system are divided into three special categories based on the recommendations of experts in the field. They are soil and water variables, climate variables and agronomic recommendations, respectively. The figure 2 shows the overall system functions and the systematic approach of the proposed system methodologies. The inputs contained in this figure 2 are water molecules analysis report, soil macro \& micronutrient analysis report, fertilizer and season respectively.

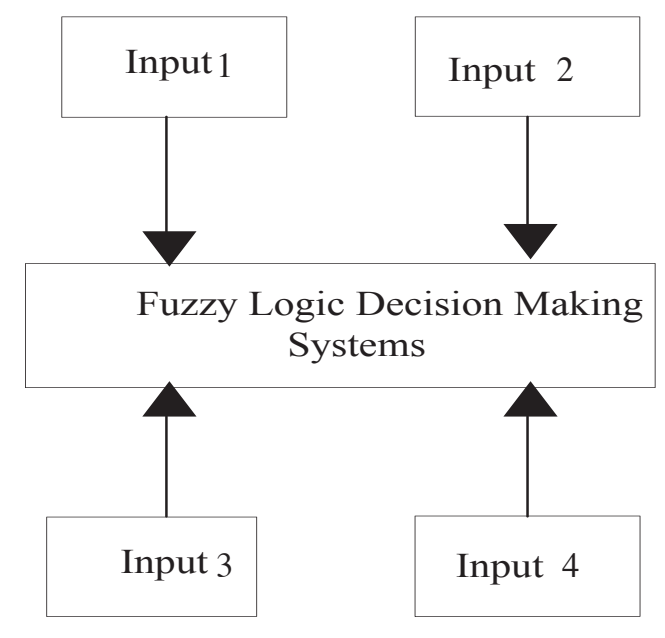

Figure 2. Structure of soil fertility fuzzy system

The nature of the soil data for this work were collected from the TamilNadu state Agriculture University, Department of Soil and Water Conservation which is examined and studying the soil texture and clay percentages and various soil parameters all over TamilNadu and the climatic parameters were collected from TamilNadu groundwater board department. The daily and monthly climatic parameters were monitored during the period Jan 2013- December 2016. Among the three years, the average minimum and maximum temperature range and humidity are $27 \mathrm{oC} \& 38 \mathrm{oC}$ and $75 \%$ respectively, which has been consistent for the past few decades. The average values recorded during this period were maximum and minimum temperature, evaporation, rainfall, wind speed and wind flow. During this period the relative humidity is around $75 \%$. 
The fuzzy rule base for the preservation of the fertility of the soil can be as follows: One cycle and simultaneous implementation of the rule base can be delayed, as a results attempts to categorize the parameter from general base and divided into several sub-groups. Each sub-group has been implemented individually in parallel and implemented until it outputs arrived. This whole process is initiated to begin with the crop and the rule base also initiated on a specific crop and its type. Seasonal circumstances for other crops other than horticulture are considered most important and most importantly if the seasonal conditions for crops like paddy watermelon and muskmelon are very important. The proposed system will have multi-input and multi-output. The input in this system is 24 and it has further divided into an 8 subsystem in order to get an optimal design purpose (Prabakaran, G., D. Vaithiyanathan, and Madhavi Ganesan, 2017 \& Prabakaran, G., D. Vaithiyanathan, and Madhavi Ganesan, 2018). This system is modeled on two agro-climatic zones and is a mixture of expert advisors and experiences of two agricultural climate zone farmers. Hence, the categories that are divided into 24 inputs and its related sub-groups are given in table1. This classification is based on the Food and agricultural organization, common fertilizers for international standard and trace elements of crop production researches has proved the source of three of the nutrients needed for the plant and by our own filed experts (Aller, A. Javier, et al, 1990, The British Association, 1955).

Table 1. Variables utilized for expert system development

\begin{tabular}{|c|c|c|c|c|}
\hline S.No & $\begin{array}{l}\text { Variable } \\
\text { Category }\end{array}$ & Variable Type & Variable Name & Unit \\
\hline \multirow[t]{3}{*}{1} & & Primary & Phosphorus & ppm \\
\hline & & \multirow[t]{2}{*}{ Nutrient } & Potassium & ppm \\
\hline & & & Nitrogen & ppm \\
\hline \multirow[t]{3}{*}{2} & & Secondary & Calcium & ppm \\
\hline & & \multirow[t]{2}{*}{ Nutrient } & Magnesium & ppm \\
\hline & & & Sulphur & ppm \\
\hline \multirow[t]{3}{*}{3} & & Micro & Iron & ppm \\
\hline & & \multirow[t]{2}{*}{ Nutrient } & Zinc & ppm \\
\hline & & & Manganese & ppm \\
\hline
\end{tabular}




\begin{tabular}{|c|c|c|c|c|}
\hline & & & Copper & ppm \\
\hline & & & Boron & ppm \\
\hline & \multirow{12}{*}{$\begin{array}{l}\text { Input } \\
\text { Variables }\end{array}$} & & Molybdenum & ppm \\
\hline 4 & & $\begin{array}{l}\text { Climatic } \\
\text { Parameters }\end{array}$ & Rainfall & $\mathrm{mm}$ \\
\hline & & & Temperature & ${ }^{0} \mathrm{C}$ \\
\hline & & & Humidity & $\%$ \\
\hline 5 & & $\begin{array}{l}\text { Water property } \\
\text { Variables }\end{array}$ & - & - \\
\hline \multirow[t]{4}{*}{6} & & $\begin{array}{ll}\text { Soil Property } \\
\text { Variables }\end{array}$ & $\mathrm{OM}$ & - \\
\hline & & & Soil pH & - \\
\hline & & & $\begin{array}{l}\text { Soil Electrical } \\
\text { Conductivity }\end{array}$ & $\mathrm{mc}^{-1}$ \\
\hline & & & Soil Type & - \\
\hline \multirow[t]{3}{*}{7} & & Seasonal Variables & Khar if & - \\
\hline & & & Rabi & - \\
\hline & & & Summer & \\
\hline
\end{tabular}




\begin{tabular}{|c|c|c|c|c|}
\hline 8 & & $\begin{array}{l}\text { Pest Incidence } \\
\text { Variable }\end{array}$ & Pest Incidence & - \\
\hline 9 & Output & Soil fertility Variable & Soil fertility & - \\
\hline 10 & Variables & Productivity Variable & Productivity & - \\
\hline
\end{tabular}

Based on the 24 inputs the fuzzy rule has been developed as it was followed by (Prabakaran G, Vaithiyanathan D \& Madhavi Ganesan, 2018). The study of the importance of primary, secondary, microorganism's disorders and its various challenges was also studied (Alloway, Brian J, ed, 2008, Fageria, N. K., V. C. Baligar, and R. B. Clark,2002 \& Rakshit, Amitava, et al. 2020). Furthermore, the nutritional details of this area have been confirmed that this soil should not be affected by such nutrients.

\section{RESULTS \& DISCUSSION}

In each Agro Climatic Zone (ACZ), the cultivation method for farmers is entrusted and such input has been applied to the proposed decision support system. The fuzzy logic rule can be defined as an if-then construct. This procedure is governed separately from the variables that are categorized separately from the constants to the final output supervised by the constants. For instance, the climate parameters have been built into 27 rules comprising temperature, rainfall and humidity and were only a function rule set as feasibility enforcer. The most relevant point is that seasonal conditions have been very favorable for the highest yield while at the same time the seasonal quantities of nutrients are not achieved high yields if the primary, secondary and micronutrients do not have specific quantities. Due to the incredible divergence in each farmland, the circumstances in each ACZ can be transformed into compounding constituents and the size of each parameters change the whole system becomes a harder system and it requires a very large computer computation capability. Therefore, the variables required for plant growth with 8 sub-type inputs and 2 outputs of dominant properties to protect the system from such difficulty. Experts' advice and their opinion based on fuzzy rules based on maximum production are farmed into the $[0,1]$ range. Finally, the intellectual details were drawn up by the field scientist and the information received from the farmers who cultivated such crops. In some of the extraordinary cases, the producers are also the knowledge consultants, and their inputs are integrated into the system design process. As far as the aforesaid areas are concerned, the subsidies of agriculture are divided by the merit and its divisions based on appropriate global practices. The Substrate molecules that continue to play an important role in plant growth, which are often called primary, secondary and micronutrient have been separate entities. For example, the soil sample of a land was tested for tomato cultivation and the field experts were advised to the farmer to harvest the crop. The inspection parameters of a separate land report are in table 2. 
Table 2. Sample Soil Nutrients analysis Report.

\begin{tabular}{|l|l|}
\hline Parameters & Rating \\
\hline pH & Neural \\
\hline Electrical Conductivity & Harmless \\
\hline Organic Matter & Low \\
\hline Nitrogen & Medium \\
\hline Phosphorus & Ideal \\
\hline Potassium & Medium \\
\hline Calcium & Low \\
\hline Magnesium & Medium \\
\hline Sulfur & Mow \\
\hline Minc & \\
\hline Copper & \\
\hline
\end{tabular}

In addition, some of the rules heuristic were enacted by the experts in consultation with the circumstances. Because the soil fertility and crop production were simultaneously compounded by target it will need to make more changes in the general practice of journey. The peasantry earned very high returns was the pretense of an interview with them, and that this interview was conducted in their positions and transparency. In addition, this research has also revealed that their agricultural land was in the same resource without any hardship. The farmers claimed that they had cultivated high yields in this method. We conducted an open circuit discussion with the farmers to find out the truth about the essence of research. The most important thing to note is that they have benefited from all the ways without affecting soil fertility. 


\section{Comparative Analysis}

This systematic approach to maintaining soil fertility is not set up taking into account on only one of the nutrient factors or climatic factors. Instead, the system is a combination of both nutritional and climatic factors. Prior to this proposed method, the fertility of the soil was maintained with site-specific nutrient management, which was a significant shortcoming, in that it addressed only one of the primary nutrients, secondary nutrients and trace elements in terms of nutrients. All nutritional factors, climatic factors and other risk factors are taken into account in this proposed system. Under such circumstances, they were also tested at the field level and verified through discussions with farmers that the soil fertility had increased. Table 3 provides the same details.

Table 3. Comparison between the various methods

\begin{tabular}{|c|c|c|c|}
\hline System & System Commitment & Soil fertility & Demerits \\
\hline $\begin{array}{l}\text { Integrated } \\
\text { management } \quad \text { system } \\
\text { Biramo, Geremew. } \quad 2018\end{array}$ & NPK alone considered & Increased & Limited factors \\
\hline $\begin{array}{lr}\text { Soil } & \text { fertility } \\
\text { improvement } & \text { system Fu, } \\
& \\
\text { HaiMei, et al. } & 2020\end{array}$ & $\begin{array}{l}\text { Nitrogen alone } \\
\text { considered }\end{array}$ & Increased & Limited factors \\
\hline Proposed System & $\begin{array}{l}\text { Micro, Macro, Trace } \\
\text { elements, climate, } \\
\text { water, soil, season , and } \\
\text { pest }\end{array}$ & Increased & - \\
\hline
\end{tabular}

\section{CONCLUSION}

The soil resource has been explored from its basic structure. The fertility of the soil is the fertility of the earth and the fertility of the surrounding environment has proved to be in the soil's surface. The formulation is used as a mechanism for avoiding barriers to improve soil fertility by using fuzzy logic. After planting the first and second seasonal crops, the third season failed the repetition. It was demonstrated after the use of fuzzy technology and the first crop was grown on the basis of the percentage of minimum fertilizers. In the same way that the soil is not influenced by guided usage of fertilizers, the growth of the crop and its yields are affected at a time when the weather parameters do not cooperate as per the law of minimum. The proposed fuzzy based system will be upgraded to a stand-alone system with the help of embedded and VLSI techniques. 


\section{ACKNOWLEDGMENT}

This work was financially supported by Government of India under the scheme of National Agriculture Development Programme through Government of TamilNadu and Supported by Department of Horticulture and Plantation Crops during 2013-205.

\section{REFERENCES}

Russell, Edward John, 1913. The fertility of the soil. Vol. 72. University Press.

Sanchez, P.A., 2002. Soil fertility and hunger in Africa. Science, 295(5562), pp.2019-2020.

Banwart, Steve, 2011 "Save our soils." Nature 474, no. 7350 151-152.

Krishna KR,2002 Soil fertility and crop production.

Benincasa, P., Tosti, G., Guiducci, M., Farneselli, M. and Tei, F., 2017. Crop rotation as a system approach for soil fertility management in vegetables. In Advances in Research on Fertilization Management of Vegetable Crops (pp. 115-148). Springer, Cham.

Fu, H., Duan, Y., Zhu, P., Gao, H., Xu, M. and Yang, X., 2020. Potential N mineralization and availability to maize in black soils in response to soil fertility improvement in Northeast China. Journal of Soils and Sediments, pp.1-9.

Mazur, R., Tenywa, M., Miiro, R., Semalulu, O., Maria, R., Mocumbe, S., Abbott, E., Lenssen, A.,

Luvaga, E., Miller, B. and Burras, L., 2017. Farmer decision making strategies for improved soil fertility management in maize-bean production systems.

Pradesh, A. 2011. Indigenous knowledge of soil fertility management in the humid tropics of Arunachal Pradesh. Indian Journal of Traditional Knowledge, 10(3), 508-511.

Osbahr, H., \& Allan, C. 2003. Indigenous knowledge of soil fertility management in southwest Niger. Geoderma, 111(3-4), 457-479.

Schjoerring, J.K., Cakmak, I. and White, P.J., 2019. Plant nutrition and soil fertility: Synergies for acquiring global green growth and sustainable development. 1-6.

Stahr, K. and Clemens, G., 2017. A fuzzy logic slope-form system for predictive soil mapping of a landscape-scale area with strong relief conditions. Catena, 155, pp.135-146..

Ogunleye, G.O., Fashoto, S.G., Mashwama, P., Arekete, S.A., Olaniyan, O.M. and Omodunbi, B.A., 2018. Fuzzy Logic Tool to Forecast Soil Fertility in Nigeria. The Scientific World Journal.

Mora-Herrera, D.Y., Guillaume, S., Snoeck, D. and Escobar, O.Z., 2020. A fuzzy logic based soil chemical quality index for cacao. Computers and Electronics in Agriculture, 177, p.105624.

Alam, S.M., Naqvi, S.S.M. and Ansari, R.A.Z.I.U.D.D.I.N., 1999. Impact of soil pH on nutrient uptake by crop plants. Handbook of plant and crop stress, 2, pp.51-60.

Chen, X.P., Cui, Z.L., Vitousek, P.M., Cassman, K.G., Matson, P.A., Bai, J.S., Meng, Q.F., Hou, P., Yue, S.C., Römheld, V. and Zhang, F.S., 2011. Integrated soil-crop system management for food security. Proceedings of the National Academy of Sciences, 108(16), pp.6399-6404.

Sibuga, K. K., and K. P. Sibuga. 1987. Principles of Crop Production.

Huq, S.I. and Shoaib, J.M., 2013. The soils of Bangladesh. Dordrecht: Springer.

Jones Jr, J.B., 2012. Plant nutrition and soil fertility manual. CRC press. 
Bueno, A.F., Paula-Moraes, S.V., Gazzoni, D.L. and Pomari, A.F., 2013. Economic thresholds in soybean-integrated pest management: old concepts, current adoption, and adequacy. Neotropical entomology, 42(5), pp.439-447.

Onstad, D.W., 1987. Calculation of economic-injury levels and economic thresholds for pest management. Journal of Economic Entomology, 80(2), pp.297-303.

Šeremešić, S., Đalović, I., Milošev, D., Jocković, Đ. and Pejić, B., 2013. Maize (Zea mays L.) yield stability dependence on crop rotation, fertilization and climatic conditions in a long-term experiment on Haplic Chernozem. Zemdirbyste-Agriculture, 100(2), pp.137-142.

Government of TamilNadu Department of Economics and Statistics, 2015- Statistical Hand Book.

Smith, R.F., 1969. The importance of economic injury levels in the development of integrated pest control programs. Qualitas plantarum et materiae vegetabiles, 17(2), pp.81-92.

Ross, T.J., 2004. Fuzzy logic with engineering applications (Vol. 2). New York: wiley.

Lee, K.H., 2004. First course on fuzzy theory and applications (Vol. 27). Springer Science \& Business Media.

G. Prabakaran, D. Vaithiyanathan, Madhavi Ganesan, 2017 “A farmer-friendly initiative" Grassroots, A Journal of Press Institute of India, Research Institute for Newspaper Development.

G. Prabakaran, D. Vaithiyanathan, Madhavi Ganesan, 2018 "Fuzzy Decision Support System for Improving the Crop Productivity and Efficient Use of Fertilizers" Computers and Electronics in Agriculture, 150, 88-97.

Aller, A.J., Bernal, J.L., Nozal, M.J.D. and Deban, L., 1990. Effects of selected trace elements on plant growth. Journal of the Science of Food and Agriculture, 51(4), pp.447-479.

Trace elements in Plant Growth The British Association, 1955. Nature Publishing Group.

Alloway, B.J. ed., 2008. Micronutrient deficiencies in global crop production. Springer Science \& Business Media.

Fageria, N.K., Baligar, V.C. and Clark, R.B., 2002. Micronutrients in crop production. In Advances in agronomy (Vol. 77, pp. 185-268). Academic Press.

Rakshit, A., Singh, H.B., Singh, A.K., Singh, U.S. and Fraceto, L., 2020. New Frontiers in Stress Management for Durable Agriculture. Springer.

Biramo, G., 2018. The role of integrated nutrient management system for improving crop yield and enhancing soil fertility under Small holder farmers in Sub-Saharan Africa: A review article. Mod Concep Dev Agrono. MCDA, 547, p.2.

Fu, H., Duan, Y., Zhu, P., Gao, H., Xu, M. and Yang, X., 2020. Potential N mineralization and availability to maize in black soils in response to soil fertility improvement in Northeast China. Journal of Soils and Sediments, pp.1-9. 